\title{
Unorden
}

\section{Nudging for sustainable consumption of electronics}

\author{
/Summary Report
}

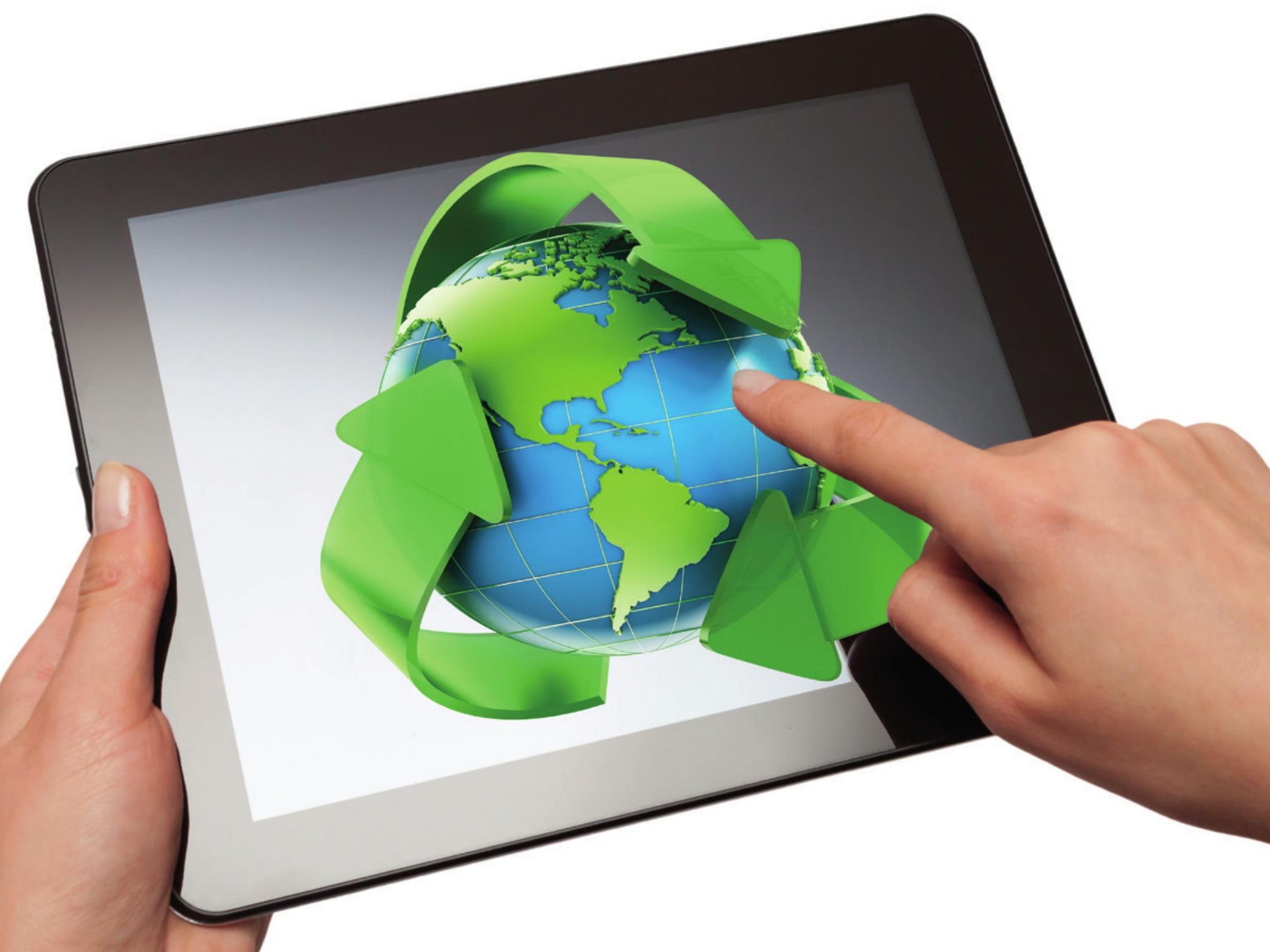


Nudging for sustainable consumption of electronics

Summary report

Amanda Stefansdotter, Jossi Steen Knudsen, Martin Flack and Pelle Guldborg Hansen

ISBN 978-92-893-4554-5 (PRINT)

ISBN 978-92-893-4555-2 (PDF)

http://dx.doi.org/10.6027/ANP2016-728

ANP 2016:728

@Nordic Council of Ministers 2016

Layout: Mette Agger Tang

Photos: Imagesubscription

\section{Nordic co-operation}

Nordic co-operation is one of the world's most extensive forms of regional collaboration, involving Denmark, Finland, Iceland, Norway, Sweden, and the Faroe Islands, Greenland, and Åland.

Nordic co-operation has firm traditions in politics, the economy, and culture. It plays an important role in European and international collaboration, and aims at creating a strong Nordic community in a strong Europe.

Nordic co-operation seeks to safeguard Nordic and regional interests and principles in the global community. Common Nordic values help the region solidify its position as one of the world's most innovative and competitive.
Nordic Council of Ministers

Ved Stranden 18

DK-1061 Copenhagen K

Phone (+45) 33960200

www.norden.org 


\title{
Nudging for sustainable consumption of electronics
}

Short version of main report

\author{
Foreword \\ Summary \\ Sustainable consumption and current policy instruments \\ Nudging for sustainable consumption \\ 18 Nudging as a part of a larger package of policy instruments
}

20 Recommendations 


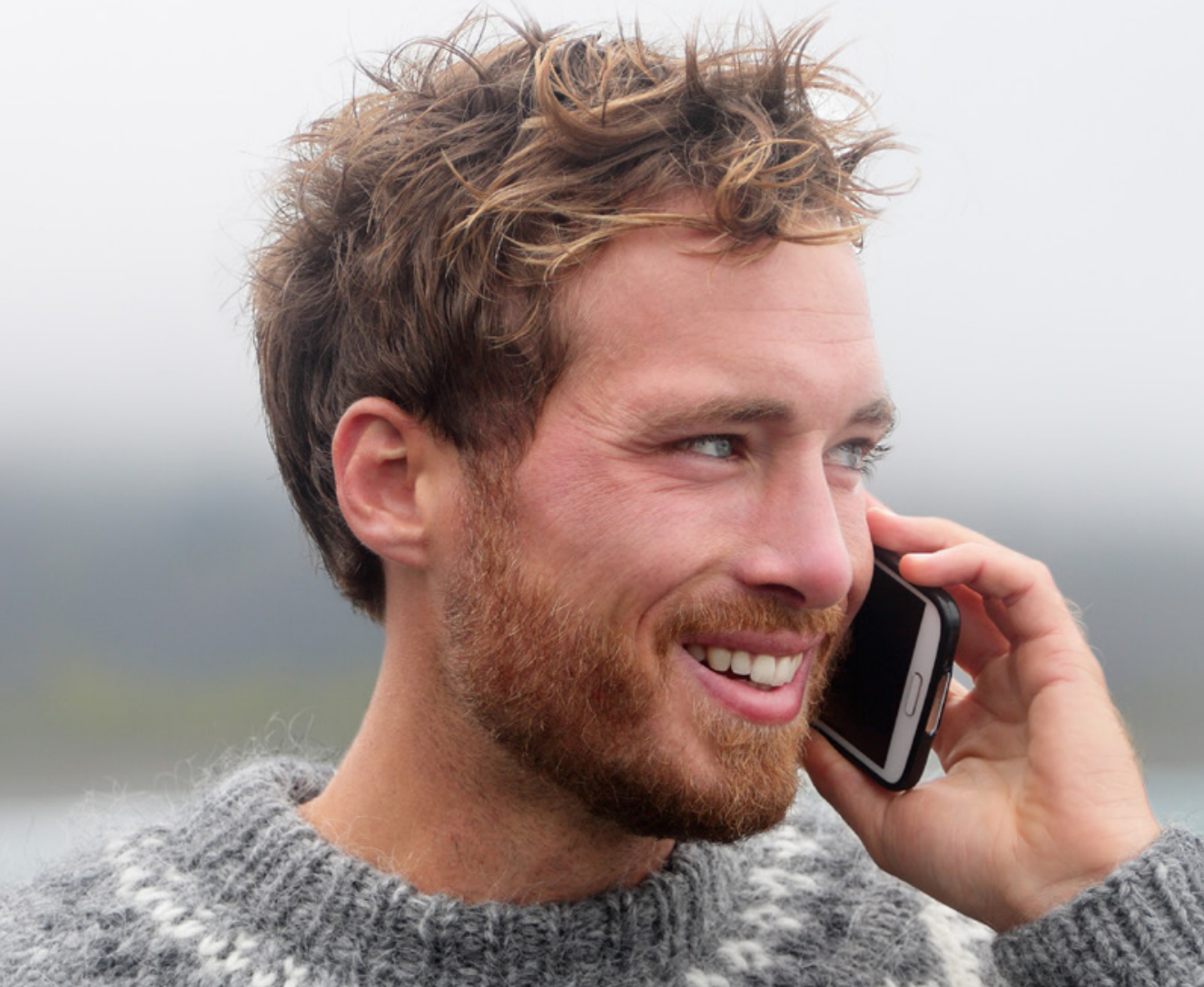

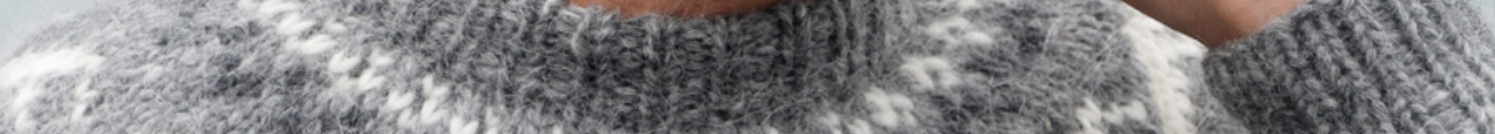

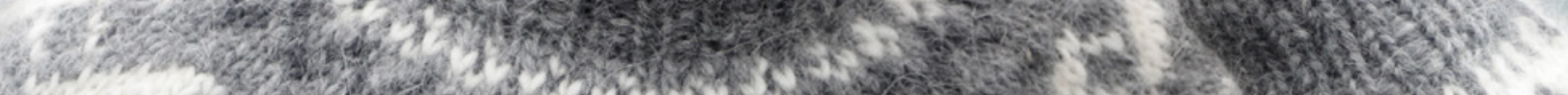

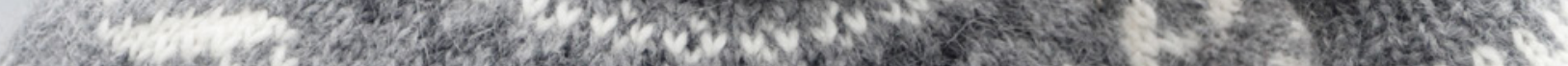

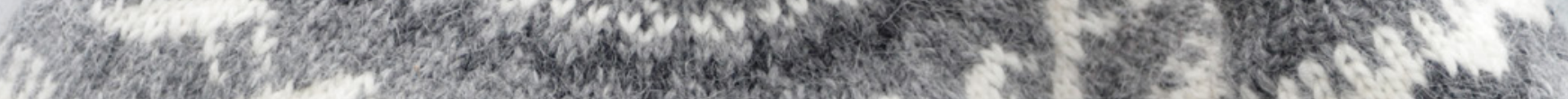

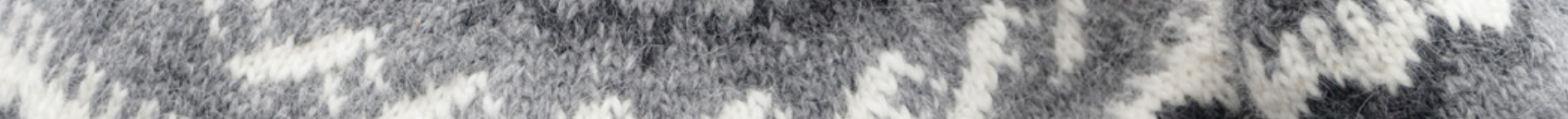
6. (2)

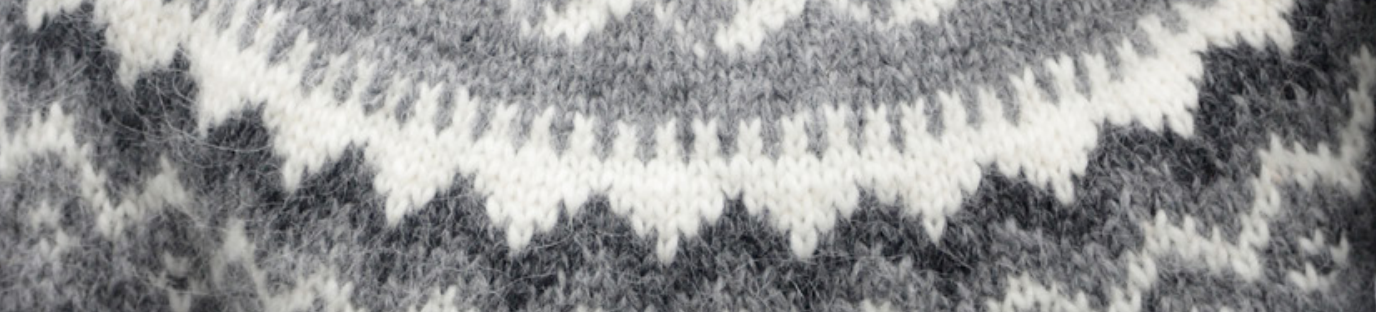

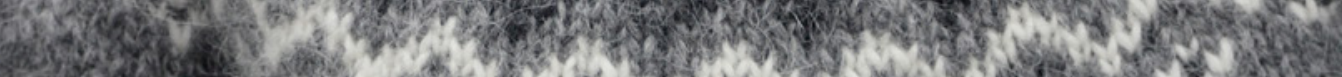
15y

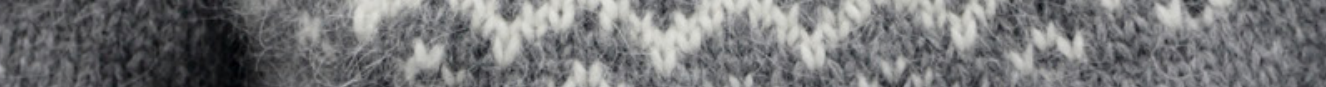

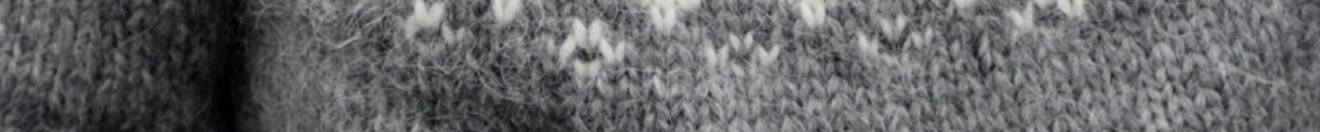

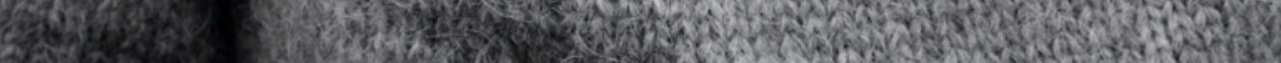
$\frac{1}{4}$

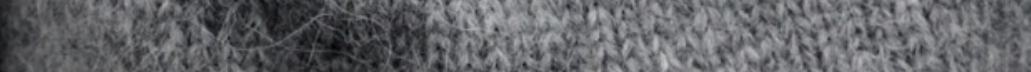

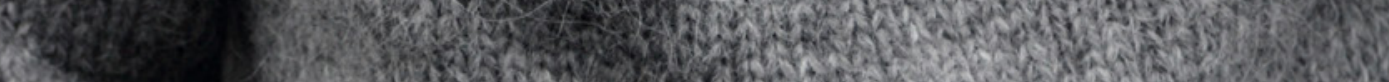
45.

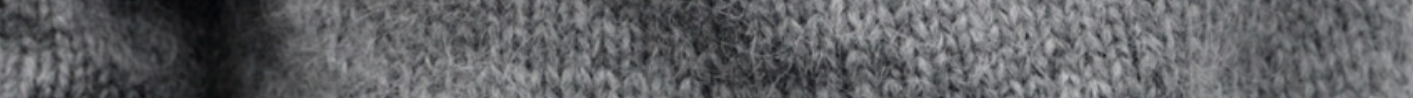

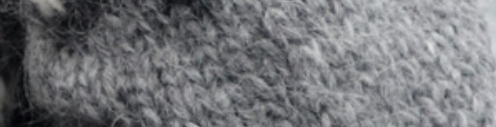

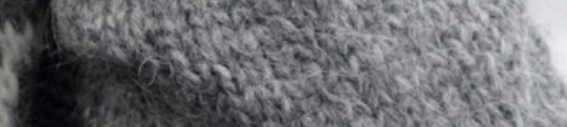

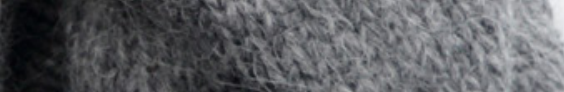

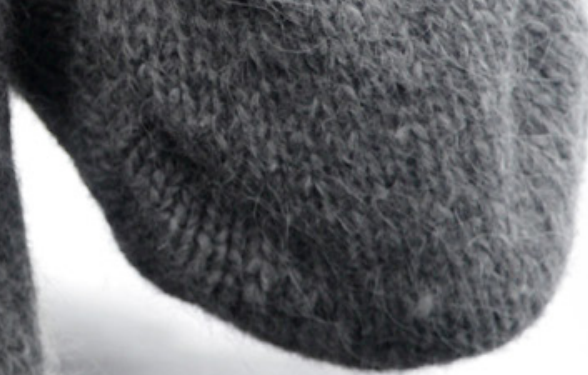




\section{Foreword}

The Nordic Council of Ministers through its working groups, the Nordic Waste Group (NWG) and the Working Group for Sustainable Consumption and Production (HKP), commissioned Copenhagen Economics to conduct a study of how recent insights from behavioural economic research can increase sustainable consumption of electronics. The study focuses specifically on nudging - a way to encourage or "nudge" consumers towards more sustainable consumption choices - and contains among other things an experiment of using nudging to increase sustainable consumption on mobile phones among young people.

The project was carried out by a project group consisting of consultants from Copenhagen Economics in both Sweden and Denmark, with Amanda Stefansdotter as project manager, and in cooperation with Pelle Guldborg Hansen at Roskilde University.

This is a short version of the main report TN2016:511 Nudging för hållbar konsumtion av elektronikprodukter, which was published in Swedish in March 2016.

The HKP Group would like to express its appreciation for a job well done and end results of interest.

March 2016

Ari Nissinen, Chair of the HKP Group

Head of unit Environmental Efficiency, Finnish Environment Institute 


\section{Summary}

Today's production and consumption patterns deplete the Earth's resources, and create waste that often contributes to extensive negative environmental and social consequences. Electronic products like computers, televisions and mobile phones are an important part of this. Increased consumption of electronic goods causes a number of environmental problems, such as local environmental and health problems associated with the extraction of materials used in electronics and in the management of electronic waste, as well as increased electricity consumption.

The main measure to offset the trend of increased consumption of electronics is producer responsibility, which means the seller of any electronic good has the responsibility for the waste generated by the sale. There is a growing awareness, however, that policies targeting the supply side (production) need to be increasingly complemented by measures targeting the demand side (consumption). Here, new knowledge from behavioural economics research can contribute to providing better predictions of how consumers behave, and affect these behaviours in a more sustainable direction.

In this report, we focus on the possibility of using behavioural economic insight, focusing specifically on so-called nudging, to increase sustainable consumption of electronics. Nudging can be defined as a way to design a situation of choice and the way options are presented (also called choice architecture), in order to change people's behaviour in a predictable way without any elimination of opportunities or change of incentives. This design can be used to nudge consumers towards more sustainable consumption choices. We focus both on the consumption of electronics in general, and in a pilot study on a specific category of consumer behaviour regarding electronics: consumption of mobile phones in the age group 19 to 28 years. A number of observations indicate that nudging can be useful to reduce consumption of electronics among young people, but that the mobile phone market's structure may potentially prevent the application of the results. In addition to further studies from a consumer perspective, an analysis from the perspective of producers and resellers in the mobile phone market is needed to fully benefit from the findings.

The main policy implications of the study's results applies to three different categories of actors: 1 ) governments in the Nordic countries, 2) implementers of the policies that the governments adopt and 3) evaluators of various efforts related to nudging. For governments, the strategic discussion of sustainability policy should include nudging as a potential tool. Strategies to increase sustainable consumption should be based on solving the identified problems, and defining how. Nudging can be an independent part of this, but can also be a part of an overall package of policy instruments, for example as a complement to other policy instruments or as a way of amplifying their effect. Implementers should work with nudging insofar as it fits into their overall mission. We interviewed representatives mainly at a municipal level in Sweden, who are interested in using insights from behavioural economics but lack knowledge of how they can do so. A general guide to nudging for environmental work could contribute to greater knowledge and consensus on the benefits and challenges of nudging. Lastly, evaluators should carefully gather information that enables evaluation of and learning from every nudging project. 


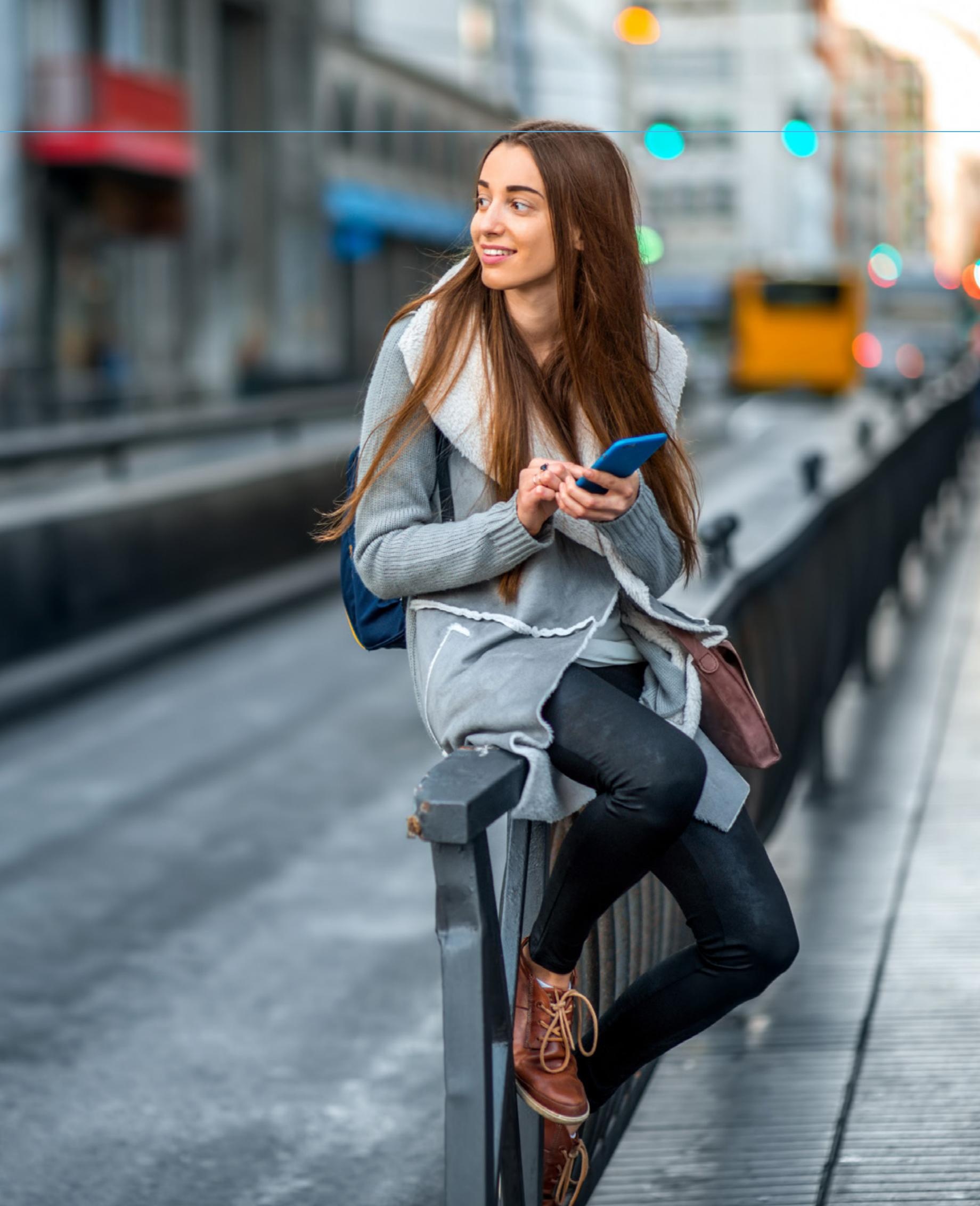




\section{Sustainable consumption and current policy instruments}

Consumption of electronics in the Nordic countries has doubled in the past two decades, which has led to a corresponding increase in the amount of electronic waste. Electronic products like computers, televisions and, not least, mobile phones, are an important part of this. Statistics from MobilTeleBranchen show, for example, that nearly four million mobile phones were sold in Sweden in 2013, which is almost a 17-fold increase in 20 years; see Figure 1.

Valuable materials contained in electronic products are lost if these are not recycled. Greater use of electronics also entails a number of environmental and social problems, such as local environmentand health-related problems associated with the extraction of materials used in electronics and in the handling of electronic waste, as well as higher electricity consumption. To counter this development, a growing number of efforts have been introduced in the Nordic region and the EU to prevent electronic waste generation. The main measure to offset the trend of increased consumption of electronics is producer responsibility, which means that the seller of any electronic good has the responsibility for the waste generated by the sale. The objective is to minimise the environmental impact of electronic waste and to

Figure 1

Total number of mobile phones sold in Sweden, 1993 to 2014

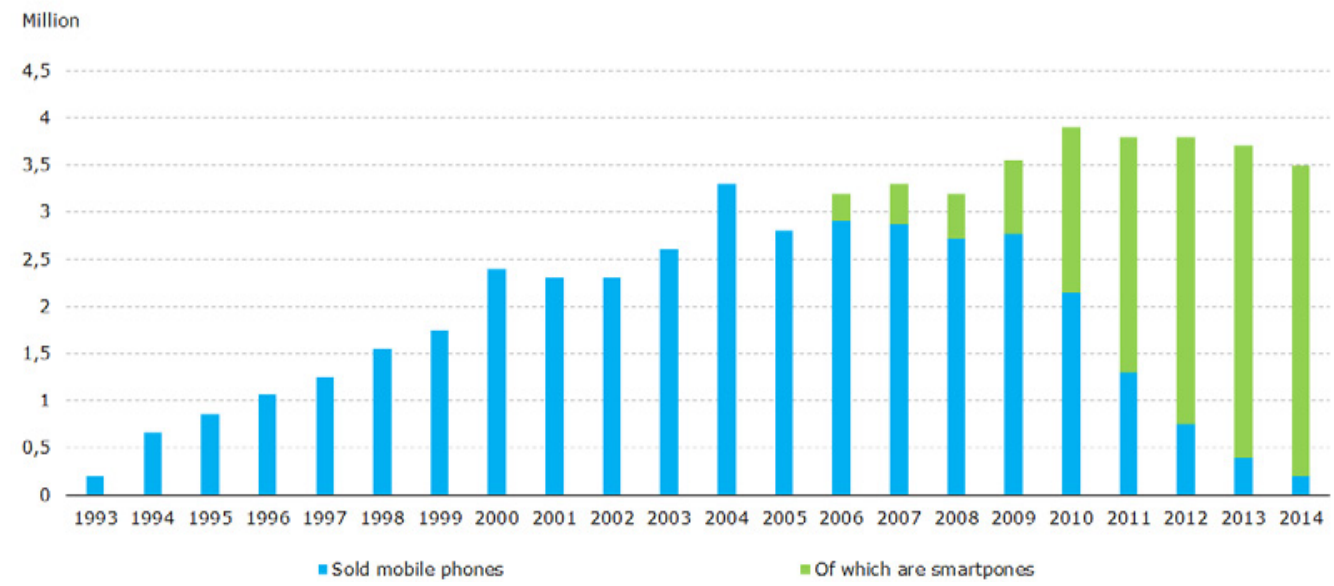

Source: Copenhagen Economics based on MTB (MobilTeleBranschen). 
manage in an environmentally correct manner. In an optimal situation, all waste is returned to production to create a circular flow in electronics production. Figure 2 illustrates the difference between a linear production chain and a circular equivalent.

There is a growing awareness, however, that policies targeting the supply side (production) need to be increasingly complemented by measures targeting the demand side (consumption). Here, new knowledge from behavioural economics research can contribute to providing better policy. Most consumer-oriented tools for encouraging a more sustainable consumer behaviour derive from a view of consumers as economically rational. According to this view, consumers behave in a way that creates the greatest possible benefit for themselves by processing all available information (such as information on the origins and costs of products). Unsustainable consumption arises when the consumer is not aware of the environmental effects of his or her actions for example, or does not pay for all costs that he or she gives rise to through his or her consumption. According to a traditional economics perspective, the solution in these two cases may be to provide more information and/or include costs for environmental damages in the price of goods through a

Figure 2

From linear to circular consumption
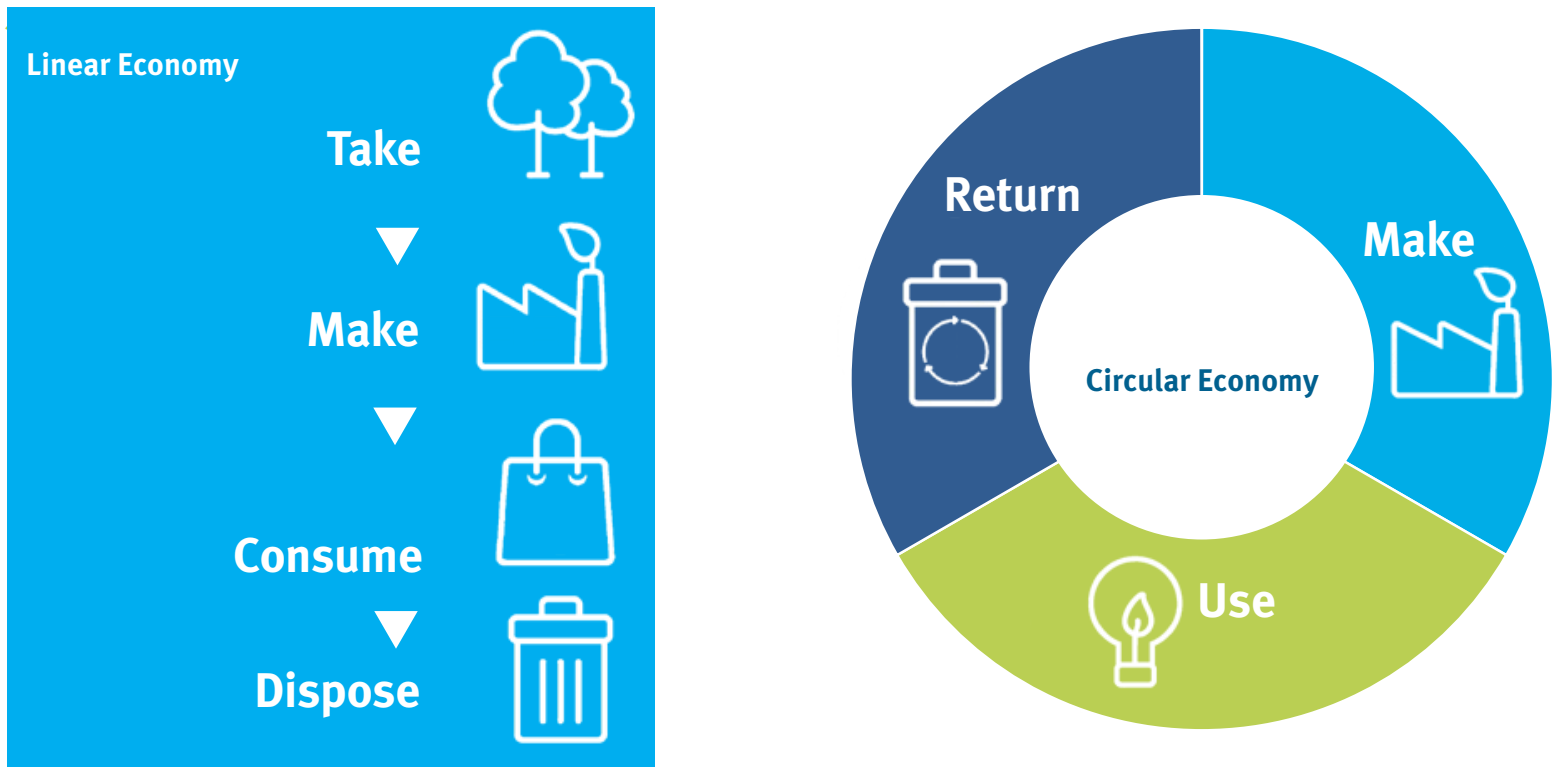
tax. Such solutions rely on people's cognitive ability to process information and make rational choices based on it.

In many cases, consumers are rational economic actors. People generally respond to higher prices by buying less of the more expensive product, and information (of for example environmental effects) is a prerequisite for individuals to be able to make sustainable choices. However, there are also exceptions, when people act both more and less sustainably than what is explained by economic theory. For example, studies have shown that people are often aware of the possibility to put value on, have positive attitudes to, and often have the intention to act environmentally friendly, which according to theory should make them act in accordance with these preferences. However, in many cases, these decisions are not translated into action. Factors such as a lack of enterprise, mental shortcuts and habits may mean that consumers do not always choose the superior alternative in an objective sense, and in accordance with their own preferences. By understanding and taking consumers' actual behaviour into consideration, decision makers can shape policy to achieve set targets in a cost-effective manner.

\footnotetext{
${ }^{1}$ The term electronics includes products that give rise to electrical waste according to Directive 2012/19/EU. This kind of waste is also known as waste electrical and electronic equipment (WEEE), and is defined as "waste that is comprised of or contains electric and electrical equipment". Specific product categories in the directive are large household appliances, small household appliances, IT and telecommunications equipment, consumer equipment and photovoltaic panels, lighting equipment, electrical and electronic tools (with the exception of large-scale stationary industrial tools), toys, leisure and sports equipment, medical devices (with the exception of all implanted and infected products), monitoring and control instruments and automatic dispensers.
} 



\section{Nudging for sustainable consumption}

The behaviours that lead to undesirable outcomes can be counter-acted with nudges - how a situation of choice is designed and options presented (also called choice architecture). The objective of nudging is to change behaviour in a predictable manner without limiting consumer options, or significantly changing economic incentives. This can for example be a matter of reminding environmentally aware people of their environmental values through labelling systems, or creating conditions for greater concentration and thoughtfulness in an otherwise routine choice.

This report investigates how nudging has been used and can be used to increase sustainable consumption of electronics. Here, sustainable consumption is defined as:
- buying fewer electronics.

- buying more environmentally friendly and/or longlived electronics.

- $\quad$ using products one owns longer.

- reusing electronics to a greater extent.

- recycling worn-out products.

The results show that there is a theoretical potential to use nudging to increase sustainable consumption, mainly through reduced purchases of new electronics, but also by encouraging individuals to use products longer and recycle more (for example by increasing repairs) and in decisions on recycling. However, as far as we know, no scientific experiments have been done on electronics consumption with specific focus on behavioural economics.

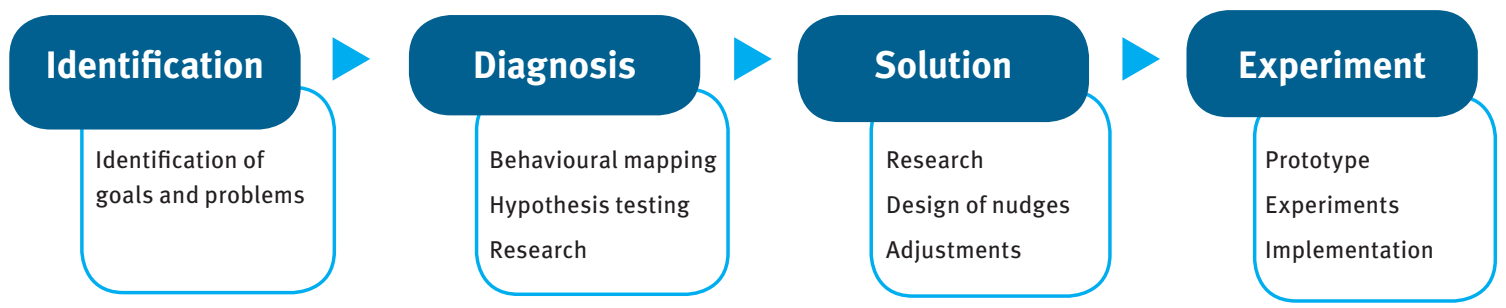


To investigate the potential impact of nudging for consumer behaviour in a specific market, we conducted a pilot experiment that concerns consumption of mobile phones among people aged 19 to 28 . To start, a behavioural survey was carried out on how young people act when they make purchases, use and recycle mobile phones. We thereafter formulated and tested nudges aimed at increasing sustainable behaviour. The project stages are illustrated in the figure on page 12.

Based on the results of the pilot study, we find that nudging can potentially have an impact on sustainable consumption of mobile phones among young people, especially by increasing repairs and purchases of used phones. Since this is a pilot study, the results should be interpreted with caution, but they provide an indication of the potential. Young people seem to have a preference for acting sustainably - for example, many want to repair their mobile phone when it breaks - but cannot or do not always do so. Presenting "green" alternatives at the time of purchase can play a role in helping them act according to their preferences. Our experiments (although done in a hypothetical purchasing situation) show that a "seller" that only presents new mobile phones induces a purchase of a new phone in 29 per cent of the cases. A seller that presents new mobile phones and a green alternative (repairs or fixing the old mobile phone) induces a purchase of a new phone in 11 per cent of the cases; see Figure 3. The difference is statistically significant. The active offering also got more consumers to choose what was offered actively. Among the respondents,

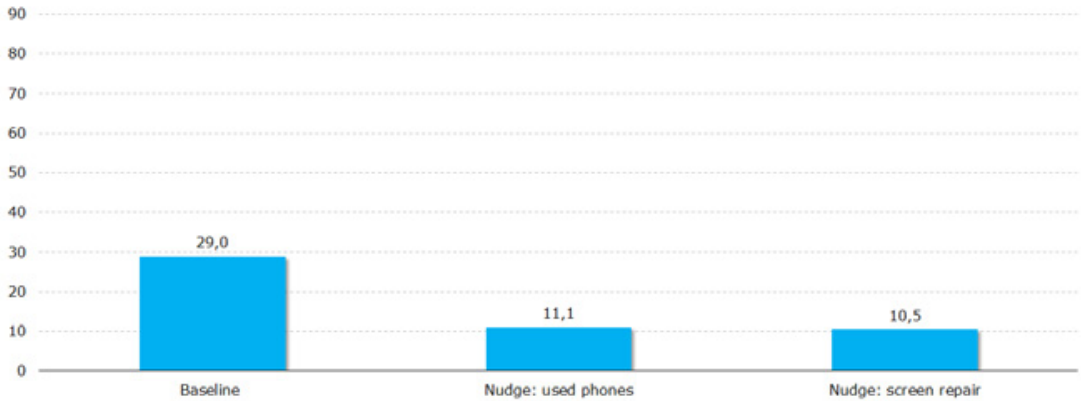

Baseline

\section{Figure 3}

Purchase of a new mobile phone with nudging for used phones and screen repair. Proportion (per cent) that choose to buy a new mobile phone.

Note: The results for the reference scenario differ from the other two categories at a 5-per cent level of significance with a two-sided T test. 
four per cent chose to buy a used phone when this alternative was available, but not actively offered, and 29 per cent when a "used phone alternative" was presente alongside of the new phones. For screen repair, the corresponding figures were 67 per cent without a nudge and 87 per cent with a nudge. This difference is also statistically significant. As the experiments were carried out for a hypothetical purchasing situation, these shares should be interpreted with caution. For example, we found in the behavioural survey that individuals on average choose to repair a broken phone in less than 67 per cent of the cases when it is possible and without a nudge, which indicates that the results do not fully reflect reality. This is also the foremost disadvantage of questionnaire studies - the researcher cannot be certain that the survey responses reflect actual behaviour. This disadvantage is reduced, however, when the questionnaire study is designed as a randomised, controlled experiment with a control and treatment group as in this case. In such an experiment, the absolute levels of the gathered answers are not the most important, but rather the difference in the levels between the treatment and control group (for example if the nudged treatment group more often chooses to repair their phones). Biases in the questionnaire study are neutralised, since the biases are likely the same in both the treatment and the control group.

The results of the experiments also show that leasing seems to be an attractive alternative for some of the respondents. Increased leasing is, however, not necessarily desirable from an environmental perspective. On one side, increased use of leased phones can create incentives for companies to manufacture more long-lived products. On the other, there is a risk that consumers trade their leased phone for new ones more often (for example, when a new model is introduced on the market), which can increase the turnover of mobile phones at an aggregate level. These returned used phones could then, however, be leased out to somebody else, and if demand is strong enough, a smaller number of new phones may be needed for the population as a whole. The net impact of these counteracting effects is of course difficult to estimate.

The nudge we tested to encourage consumers to buy "green" mobile phones, rather than conventional alternatives, proved ineffective in the experiments. This can have several possible explanations. For example, economic incentives can crowd out other motives, such as the desire to act in an environmentally friendly manner. Providing a discount on an environmentally friendly product (that consumers are willing to pay more for) moves awareness to the price, which can cause the consumer to focus more on this than the fact that one is doing something good for the environment.

It is again important to emphasise that the results should be interpreted with caution as they are based on a pilot study that was done in a simulated setting, and thus has not been tested in an actual purchase situation. It is thereby not possible to say how and on what scale the results can be used. 


\section{Results of experiment in pilot study}

\begin{tabular}{l|l|l} 
Nudge & Description & Effect \\
\hline Experiment 1 & $\begin{array}{l}\text { The "repair" alternative is presented } \\
\text { in connection with the offer of a } \\
\text { new phone in a simulated purchase } \\
\text { situation }\end{array}$ & $\begin{array}{l}\text { Nudge leads to a statistically } \\
\text { significant difference }\end{array}$ \\
\hline Nudging for used phones & $\begin{array}{l}\text { The "used phone" alternative is } \\
\text { presented in connection with the } \\
\text { offer of a new phone in a simulated } \\
\text { purchase situation }\end{array}$ & $\begin{array}{l}\text { Nudge leads to a statistically } \\
\text { significant difference }\end{array}$ \\
\hline Experiment 2 & $\begin{array}{l}\text { A decoy (a non-relevant alternative) } \\
\text { is added to a simulated purchase } \\
\text { situation }\end{array}$ & $\begin{array}{l}\text { Nudge leads to a statistically } \\
\text { significant difference }\end{array}$ \\
\hline Nudging for more leasing & $\begin{array}{l}\text { A decoy (a non-relevant alternative) } \\
\text { is added to a simulated purchase } \\
\text { situation }\end{array}$ & $\begin{array}{l}\text { Nudge does not lead to a } \\
\text { statistically significant difference }\end{array}$ \\
\hline Nudging for "green phones" & &
\end{tabular}

Source: Copenhagen Economics.

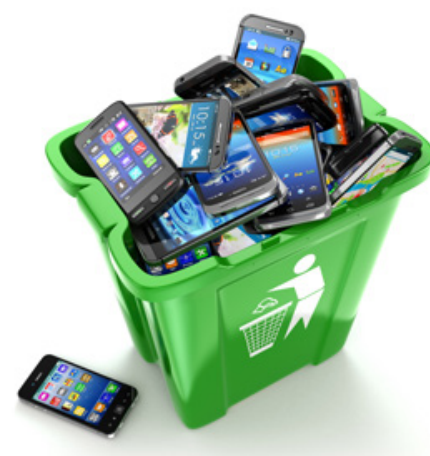




\section{Structure of the mobile phone market prevents possible use of nudging}

There is a built-in problem in translating the above findings into action: the market for mobile phones currently does not have actors with the kind of incentives required to implement the results. Mobile phone retailers today generally do not offer repairs, and offer used phones only to a limited extent. It is thereby not in their interest to present these alternatives (without broadening their offering). Reminding customer of possibilities outside the company's business would lead to reduced sales in the store, which means that the retailer does not have incentives to do so. Producers of mobile phones are also driven by commercial motives to sell large quantities and thereby make a profit, and lack in a similar way incentives to present other alternatives than new purchases. There are also a number of obstacles to sustainable consumption of mobile phones related to the structure of the market. Subscription plans offered by mobile phone retailers, which expire after a certain number of years at which point it "feels like it is time" to get a new phone, is one example. Planned obsolescence, where mobile phones become slow or unusable after a certain number of software updates, is another. Rapid technical development also makes phones outdated before their actual end of service life.
This study is based on a consumer perspective. In addition to further studies in this area, an analysis from the perspective of producers and retailers in the mobile phone market is needed to fully use the results. To apply insights about nudging for sustainable consumption of mobile phones, we need to know the cases in which the commercial motives of retailers and producers of mobile phones described above contradict socioeconomic motives of for example decreasing environmental impact, and in which cases they align. In cases where motives are not aligned nudging may possibly need to be supported by regulation of for example what information businesses need to show with regard to repair costs, used phones and "green" alternatives. When motives are aligned, interventions are probably less complicated. For example, retailers of used phones and stores that repair mobile phones can be assumed to have incentive to nudge consumers towards these alternatives, for example by displaying comparative prices between new and used phones. Markets for repair and used phones are, however, relatively undeveloped today, and need to work well in order for consumers to choose these alternatives, and benefit from the choice. 


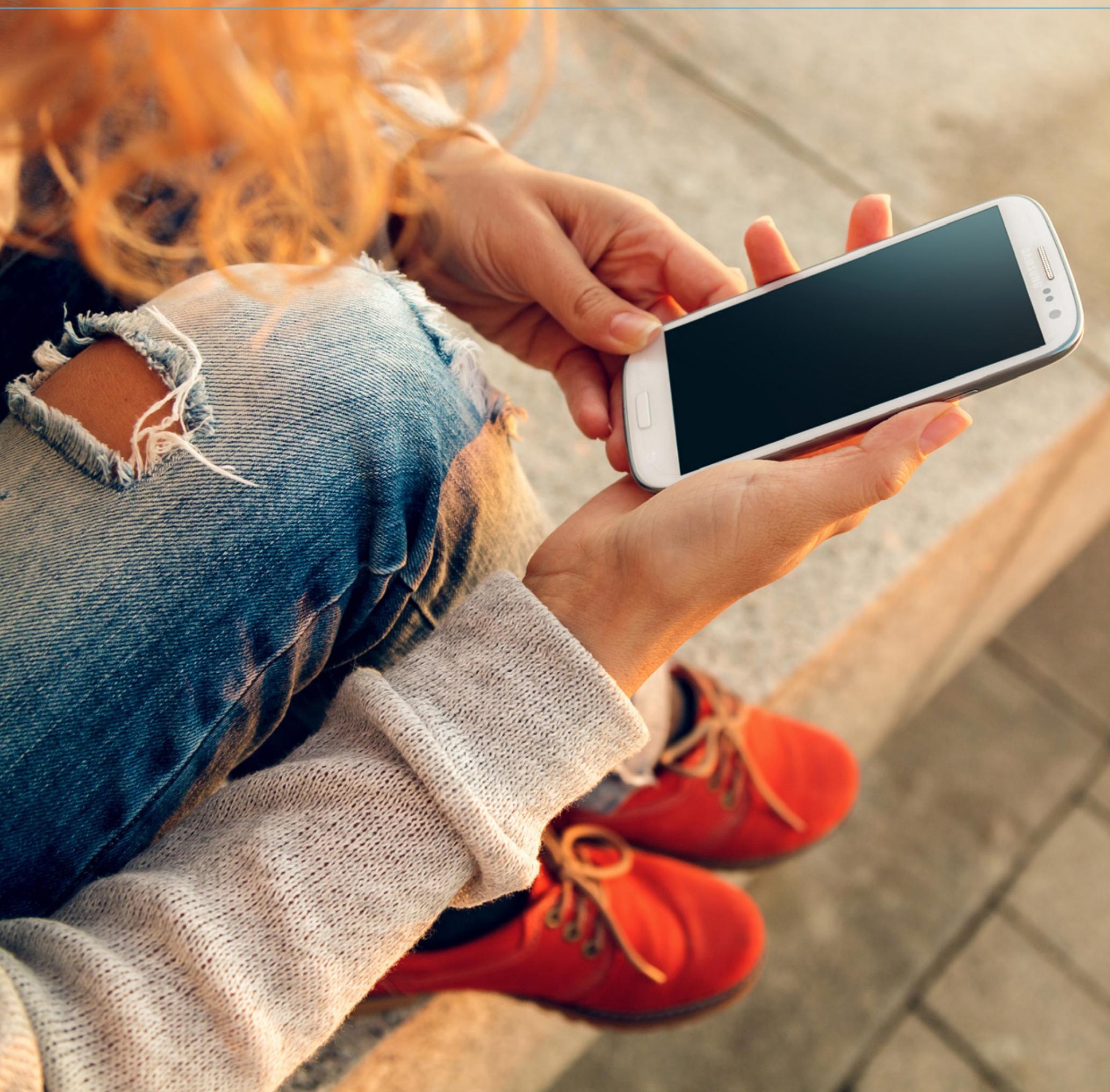




\section{Nudging as a part of a larger package of policy instruments}

A conclusion of this study is that nudging and other policy instruments do not need to exclude one another - on the contrary. According to the most used definitions (such as Thaler \& Sunstein, 2008), nudging is about changing people's behaviour while presuming that they already have the attitudes necessary to demonstrate this behaviour. For example, ecolabelling presumes that consumers are interested in consuming environmentally friendly alternatives and are willing to pay more for them. The ecolabel should only remind consumers of these values at the time of purchase. This means that nudging without underlying attitudes is not effective - being reminded of environmental values does not help if one does not share these values. ${ }^{2}$ As other policy instruments, especially information provision, aim to affect these attitudes, instruments are highly complementary. Here, nudging can be used to increase the attention given to information that may influence attitudes, or to emphasise economic differences between sustainable and less sustainable alternatives.

The figure on page 20 summarises the main policy implications of these results. The implications are segmented into three groups, based on what kind of actors they target. In the first group are governments in the Nordic countries that define environmental and sustainability policy. In the second group are implementers, and in the third are evaluators. In addition, the Nordic Council of Ministers and other Nordic organisations can help distribute knowledge about which nudging efforts are successful and which are not in the Nordic countries, and and in this way work to facilitate the learning process.

The different recommendations are described in more detail on page 21 .

\footnotetext{
${ }^{2}$ In other cases, however, it may not be clear if nudging helps individuals choose according to their own attitudes and preferences, or rather works to achieve goals set by an external party or society as a whole. Take an example where nudging is used in cafeterias to reduce food consumption and/or food waste. This can be done by replacing large plates for smaller ones, which has had a demonstrated effect on reducing the amount of food people take, and thus the corresponding food waste. While the person designing this choice situation has not asked everyone taking food in the cafeteria whether or not they want to reduce their food waste or not - this is an implicit assumption, which may not align with actual preferences. However, as the choice for the designer in this case is between nudging towards taking more food (with larger plates) or less food (with smaller plates), the latter can arguably be seen as the better choice, as there is also a socioeconomic benefit attached to reducing food waste. Importantly, nudging in this case does not limit the possibility for those who do not want eat more - they can take food several times. It is simply a way of organising the choice situation, so that the most desirable outcome is the one that most people will choose unless they have strong preferences against it.
} 


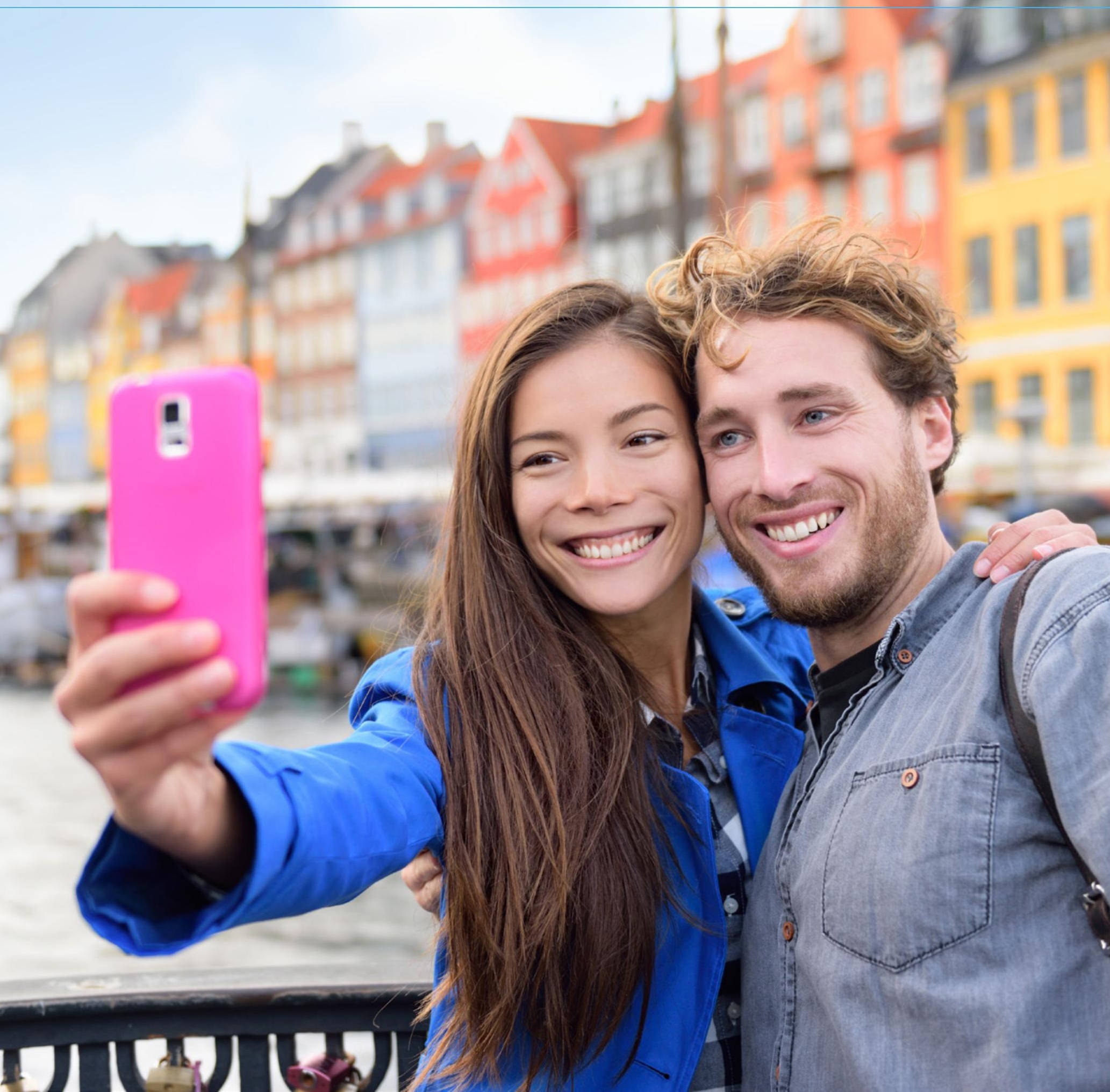




\section{Recommendations}

\section{1 \\ Nordic governments: Include nudging in the strategic}

discussions on sustainability.

Implementers: Use nudging in a way that leads to the
achievement of the sustainability strategy decided by

Implementers: Use nudging in a way that leads to the
achievement of the sustainability strategy decided by governments.

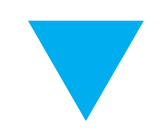
governments.

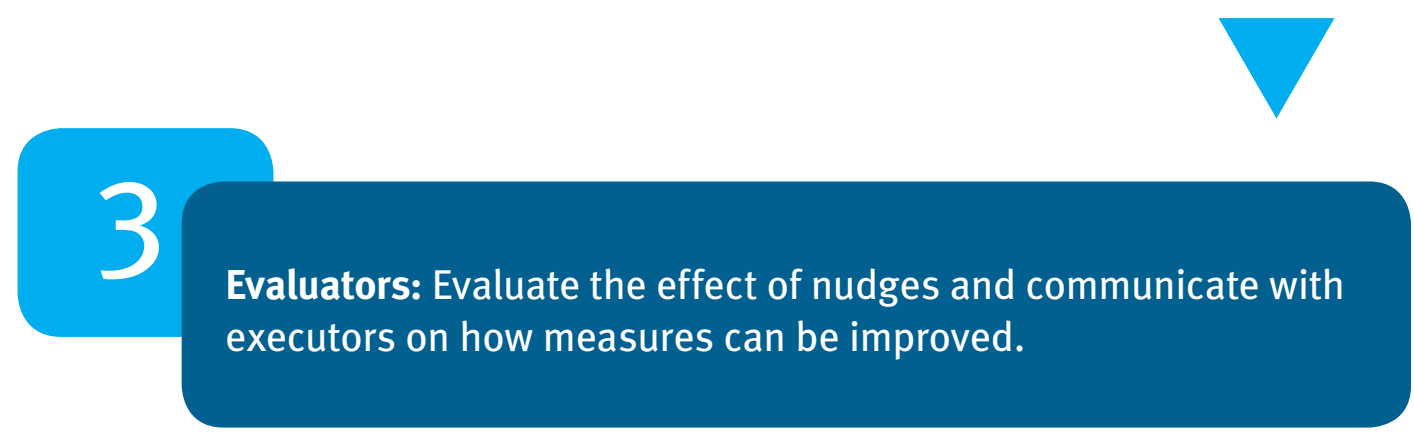




\section{Governments}

The strategic discussion of sustainability policy should include nudging as a possible tool, but should first and foremost focus on identifying problems and defining how they should be solved. Nudging can be an independent part of this, but can also be a part of an overall package of policy instruments, such as a complement to other policy instruments or for amplifying their effect. An interview study shows, for example, that persons who work for example with recycling or collection of electronics believe that improved producer responsibility or increased possibilities for repair are important instrument for increasing the collection of electronics. Here, behavioural economics or nudging are probably not the most effective tool, but can serve as a valuable complement by for example encouraging repairs.

\section{Implementers}

Implementing actors, such as municipalities or operating agencies, should work with nudging insofar as it fits into their overall mission. We interviewed representatives mainly at a municipal level in Sweden who claim to be interested in using insights from behavioural economics, but lack knowledge of how they can and should go about doing so. Thus, those who could potentially work with nudging do not seem to do so. A general guide to nudging for environmental work could contribute to greater knowledge and consensus on the benefits and challenges of nudging. Such a guide should contain clear steps - behavioural mapping, analysis and problem identification, solution/nudging design, evaluation and learning - with practical examples that can help organisations that want to work with nudging to do so in a structured manner.

\section{Evaluators}

Although there is a growing literature on behavioural economics and nudging, the areas is still relatively unexplored. consequently, the use of nudging still has limitations that need to be overcome before the method is accepted on a larger scale (side-effects, difficulties transferring nudges from controlled experiments to actual conditions, long-term effects, etc.). Collection of information that enables evaluation and learning should therefore be a central part of every nudging project. Nudges should be designed with evaluation in mind, and evaluating authorities in the Nordic countries should be given the assignment to evaluate the effectiveness of nudging efforts. To do this, evaluators need knowledge about nudging. Feedback and learning thus also needs to take place between implementers and evaluators. 


\section{See Copenhagen Economics (2015)
"Nudging för hållbar konsumtion
av elektronikprodukter" for a list
of references, and the full report in
Swedish. \\ See Copenhagen Economics (2015)
"Nudging för hållbar konsumtion
av elektronikprodukter" for a list
of references, and the full report in
Swedish. See Copenhagen Economics (2015)
"Nudging för hållbar konsumtion
av elektronikprodukter" for a list
of references, and the full report in
Swedish. \\ See Copenhagen Economics (2015)
"Nudging för hållbar konsumtion
av elektronikprodukter" for a list
of references, and the full report in
Swedish.

tin

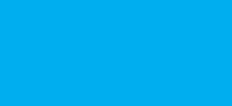
$x^{2}$

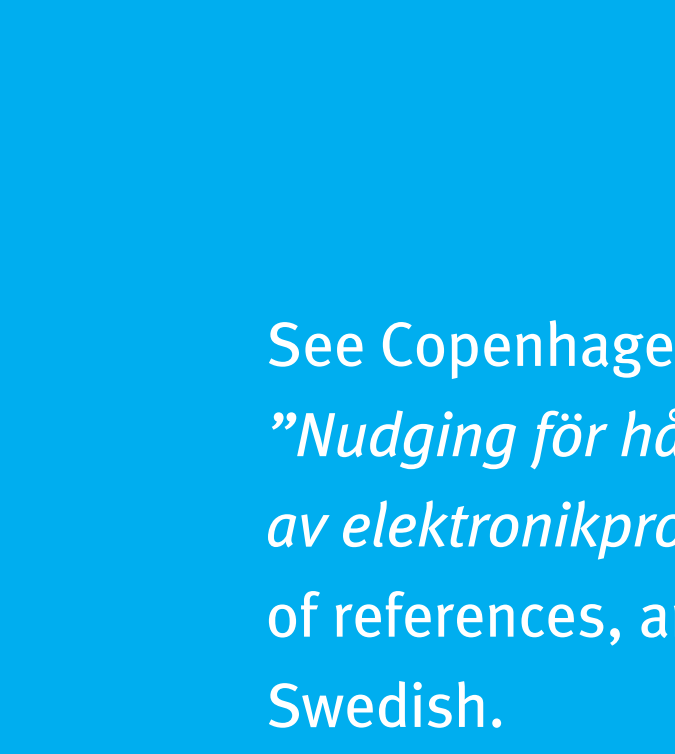

(1)
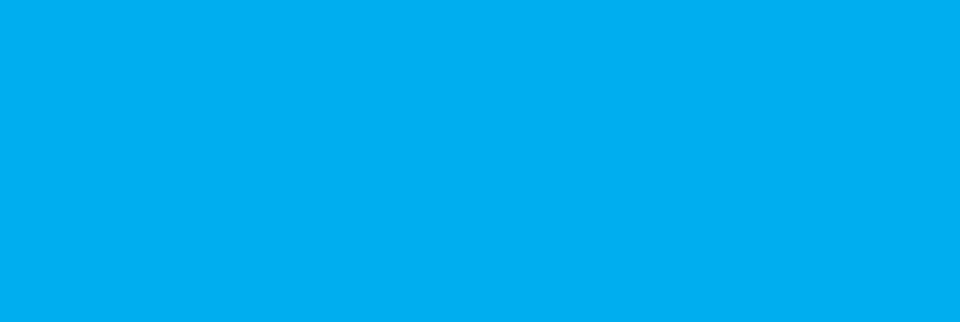

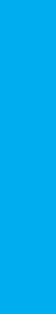

$+2$ 


\title{
norden
}

Nordic Council of Ministers

\author{
Ved Stranden 18 \\ DK-1061 Copenhagen K \\ www.norden.org
}

Nudging is a way of benevolently pushing consumers towards more sustainable consumption choices without compulsion. The Nordic Council of Ministers through its working groups, the Working Group for Sustainable Consumption and Production (HKP) and the Nordic Waste Group (NWG), commissioned Copenhagen Economics to conduct a pilot study of how this knowledge can be applied to increase understanding of young people's consumption patterns with regard to mobile phones and how this behaviour can be influenced in a more sustainable direction using so-called nudging. A number of observations indicate that nudging can be useful to reduce consumption of electronics in the latter group, but that the mobile phone market's structure of today may potentially prevent the application of the results.

This is a short version of the Swedish TN2016:511 Nudging för hållbar konsumtion av elektronikprodukter.

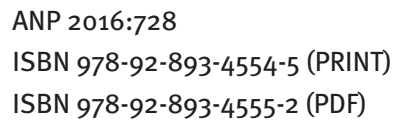

